\title{
Role of Medial Prefrontal Cortical Neurons and Oxytocin Modulation in the Establishment of Social Buffering
}

\author{
Taesub Jung, Minji Jang and Jihyun Noh* \\ Department of Science Education, Dankook University, Yongin 16890, Korea
}

\begin{abstract}
Fear-related behaviors are rigidly controlled by the medial prefrontal cortex (mPFC). The mPFC is activated by the prosocial hormone oxytocin, which plays an important role in social buffering. We used a slice patch current-clamp recording in single- and pair-exposed rats who were subjected to electric shocks, to determine the cellular mechanism of the action of oxytocin in the mPFC under social buffering conditions. Pair-exposed rats showed a significant reduction in both freezing and passive avoidance behaviors compared to single-exposed rats. It was observed that input resistance in pyramidal neurons decreased in both single- and pair-exposed rats than naïve rats, but input resistance in interneurons increased in pair-exposed rats than single-exposed rats. We found that the number of action potential (AP) spikes in the mPFC pyramidal neurons decreased significantly in pair-exposed rats than in single-exposed rats. The pyramidal neurons in the MPFC were similarly regulated by oxytocin in singleand pair-exposed rats, while the number of AP spikes in interneurons by oxytocin decreased in single-exposed rats, but there was no significant change in pair-exposed rats. Therefore, our findings reveal that a decrease in mPFC pyramidal neuronal activity in pair-exposed rats through social interaction induces a reduction in fear-related behavior via obstruction of fear-memory formation; however, no such reduction was observed in single-exposed rats. Moreover, we suggest that the oxytocin-mediated decrease in neuronal activity in the mPFC could facilitate social buffering.
\end{abstract}

Key words: Cortical neuron, Fear response, Oxytocin, Prefrontal cortex, Social buffering

\section{INTRODUCTION}

Social buffering plays an important role as a positive factor in the formation of social relationships and bonding [1]. Social buffering can be defined as the phenomenon of improved recovery from stressful experiences when an organism is in the company of members of the conspecific species; this phenomenon is observed in rats, mice, birds, apes, and humans. Social buffering is similarly observed in humans and improves human health as part of the benefits of social support [2]. Social buffering affects the stabilization of the emotional state, which can function to alleviate negative emotional behaviors such as anxiety and depression [3]. The posi-

Submitted August 22, 2020, Revised January 24, 2021,

Accepted February 18, 2021

* To whom correspondence should be addressed.

TEL: 82-31-8005-3842, FAX: 82-31-8021-7231

e-mail: jihyun2@dankook.ac.kr tive effects of this social buffering are the focus of several ongoing studies, but the mechanism is mainly thought to be a hormonedriven one. Moreover, the mechanisms and specific brain areas associated with this phenomenon are still insufficiently understood.

The stress-induced release of corticosterone is reduced by social buffering, while the positive effects of the social buffering process can affect conditioning or extinction of fear memory, which is classified as a stress memory [4-6]. These social bufferinginduced stress-relieving effects are mediated by various areas of the brain, such as the medial prefrontal cortex (mPFC), amygdala, bed nucleus of the stria terminalis, paraventricular nucleus, and nucleus accumbens [7]. The roles of the anterior cingulate cortex in empathy through the mirror neuron system, the prelimbic region (PL) in social recognition, and the infralimbic (IL) cortex in social memory suggest that the $\mathrm{mPFC}$ is related to social buffering associated with oxytocin [8-10]. The oxytocin receptor-expressed neurons are distributed in the mPFC, and social buffering can alter the distribution, number, and function of oxytocin neurons
Copyright (c) Experimental Neurobiology 2021. www.enjournal.org
This is an Open Access article distributed under the terms of the Creative Commons Attribution Non-Commercial License (http://creativecommons.org/licenses/by-nc/4.0) which permits unrestricted non-commercial use, distribution, and reproduction in any medium, provided the original work is properly cited. 
$[11,12]$. Moreover, social buffering induces an increase in the oxytocin receptors in oxytocin neurons in the amygdala [13]. The role of oxytocin as a social hormone and that of dopamine with reward-seeking behaviors are important for social bonding and social buffering. The mPFC plays an important role in controlling oxytocin and dopamine neurocircuitry $[14,15]$. Therefore, this study focused on the role of mPFC neurons under social buffering conditions and their change of oxytocin.

Microinfusion of an oxytocin agonist into the mPFC enhanced fear extinction, whereas the oxytocin antagonist impaired fear extinction and reversed the enhancing effect of pairing on fear extinction [16]. One study showed that oxytocin played an important role in social recognition memory: depletion of oxytocin in the $\mathrm{MPFC}$ of rats hampered their ability to distinguish between novel mice and familiar mice [17]. Excitation of the oxytocin-sensitive PFC to the connection with the basolateral amygdala (BLA) using in vivo optogenetic techniques eliminated the preference of social novelty, suggesting that this circuit is required for social recognition [18]. Therefore, it is essential to verify the modulation of the $\mathrm{mPFC}$ after exposure to oxytocin to understand the functions of the latter.

Previously, pair-exposed rats who were kept in the company of conspecific organisms for social buffering were subjected to fear conditioning and underwent a passive avoidance test to evaluate memory function and freezing behavior, to demonstrate whether social buffering induces the link between fear responses and fear memory from social stimuli during fear conditioning [19]. Previous studies have identified that pair exposure to conspecific organisms during fear conditioning helps the organism to cope with both the freezing-response and the fear memory systems; however, no study has focused on their underlying mechanism. In this study, a pair-exposed fear model was used to investigate the role of social buffering on the fear-related response and a whole-cell patch recording was conducted to verify the brain function mechanism of social buffering, with a special focus on the oxytocin modulation of the function of both pyramidal neurons and interneurons.

\section{MATERIALS AND METHODS}

\section{Animals}

Subjects were Sprague-Dawley adolescent male rats (Postnatal Days 21 42) from Orient Bio (Seongnam, Republic of Korea). All experiments were conducted by the guidelines of the ethics committee of the Dankook University Ethics Committee's Guidelines for the Care and Use of Laboratory Animals (DKU-17-033). Rats were weaned at 21 days of age and individually housed in a Plexiglas cage $(46 \times 23 \times 20 \mathrm{~cm})$ with wood bedding with a $12: 12$ h light/dark cycle (lights on at 9 A.M.). For paired shock exposure, separated weaned siblings were used. Food and water were always available. The experiments were conducted in a sound-insulated compartment with controlled temperature $\left(23 \pm 1^{\circ} \mathrm{C}\right)$ and humidity $(45 \pm 5 \%)$ following the experimental schematic timeline shown in Fig. 1A. The rats were assigned to one of the following two treated groups: (1) Single-exposed rats, which were shocked alone in a learning session; (2) Pair-exposed rats, which were shocked with their mate in a learning session; (3) Naïve rats, which were not exposed to electric shock.

$\mathbf{A}$

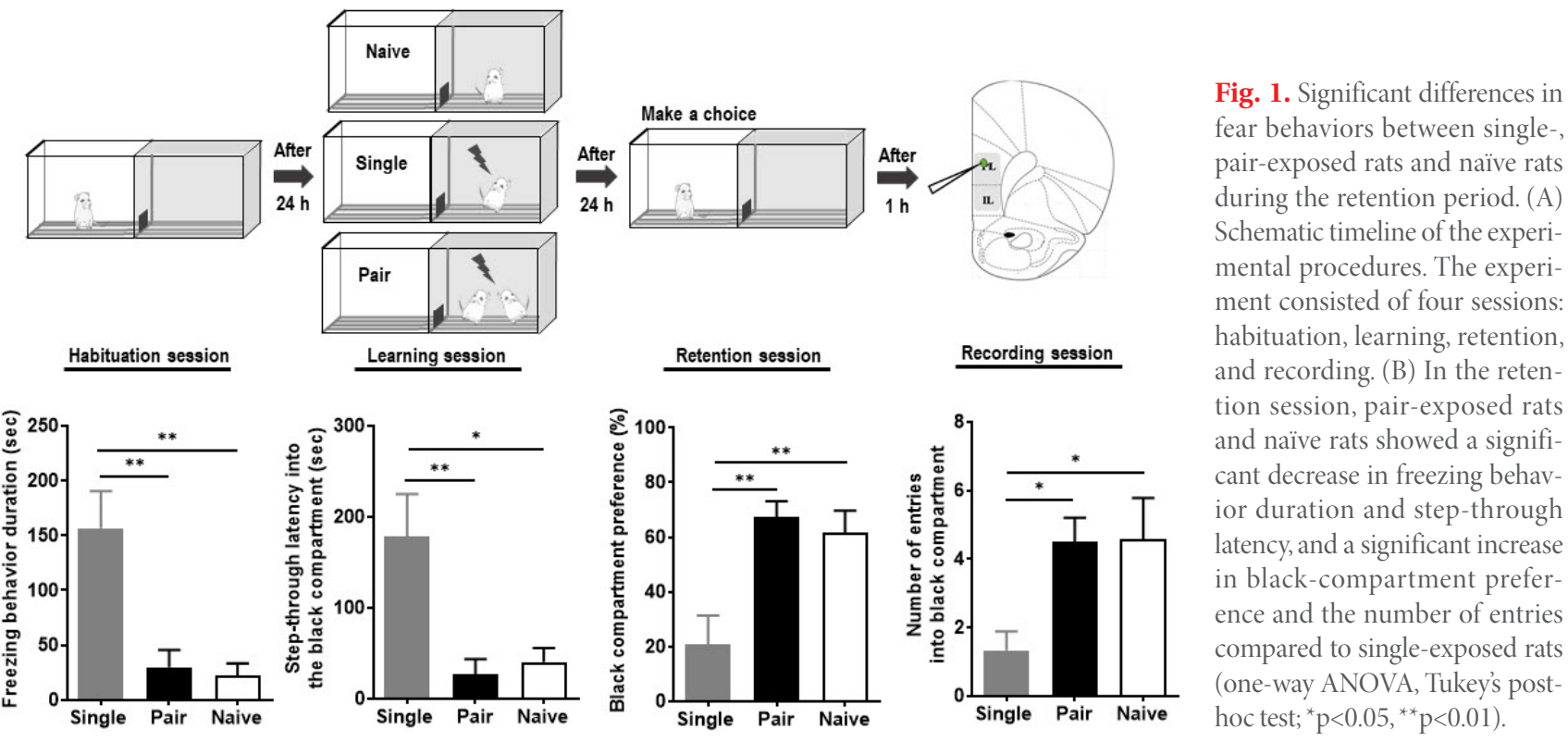




\section{Passive avoidance test}

The passive avoidance test consists of habituation, learning, and retention session (Fig. 1A). All rats habituated the test environment $10 \mathrm{~min}$. In the habituation session, rats were placed in a white compartment and could explore both black and white compartments to estimate which compartment they preferred for $5 \mathrm{~min}$. After 1 day, rats were placed in a white compartment for $1 \mathrm{~min}$ and the door which blocked gate of black and white compartment was opened. When rats passed from the white compartment to the black compartment, the door was closed and then rats could not go back the white compartment again and received electrical shock delivered through the grids ( $0.7 \mathrm{~mA}$ for $5 \mathrm{~s}$; learning session) [19]. After 1 day, rats were placed in the white compartment for 1 min and the door was opened. During the retention session, the duration of freezing, black compartment preference, number of the entry, and latency into the black compartment for 5 min were measured. The passive avoidance box was cleaned with $70 \%$ ethanol after each trial.

\section{Brain slice preparation and slice-whole cell patch current- clamp patch recording}

After passive avoidance test, brains were quickly removed and immersed in an oxygenated $\left(95 \% \mathrm{O}_{2} / 5 \% \mathrm{CO}_{2}\right)$, ice-cold artificial cerebrospinal fluid (ACSF) solution containing the following composition (in mM): $126 \mathrm{NaCl}, 3 \mathrm{KCl}, 1.25 \mathrm{NaH}_{2} \mathrm{PO}_{4}, 1.3 \mathrm{MgSO}_{4}$, $2.4 \mathrm{CaCl}_{2}, 26 \mathrm{NaHCO}_{3}$, and $8_{\mathrm{D}}$-glucose. Coronal mPFC slices $(300-\mu \mathrm{m})$ were cut using a vibratome $(5,100 \mathrm{mz}-22$, Campden Instrument, England). During $15 \mathrm{~min}$, brain slices were incubated with warm $\left(30^{\circ} \mathrm{C}\right)$ oxygenated $\left(95 \% \mathrm{O}_{2} / 5 \% \mathrm{CO}_{2}\right)$ N-Methyl-Dglucamine (NMDG) ACSF containing the following (in mM): 126 $\mathrm{NaCl}, 3 \mathrm{KCl}, 1.25 \mathrm{NaH}_{2} \mathrm{PO}_{4}, 10 \mathrm{MgSO}_{4}, 0.5 \mathrm{CaCl}_{2}, 26 \mathrm{NaHCO}_{3}$, $25 \mathrm{D}_{\text {-glucose, }} 110 \mathrm{NMDG}$, and $80.05 \mathrm{HCl}$. Then, slices were incubated with oxygenated $\left(95 \% \mathrm{O}_{2} / 5 \% \mathrm{CO}_{2}\right)$ ACSF for $>1$ h at room temperature. Recordings were performed in a submersion-type chamber $\left(2 \sim 4 \mathrm{ml} / \mathrm{min}\right.$ perfusion of oxygenated ACSF at $\left.33 \sim 35^{\circ} \mathrm{C}\right)$ mounted on an upright microscope (Nikon Eclipse FN1, Tokyo, Japan). Recorded action potential (AP) spikes in the $\mathrm{mPFC}$ region using a borosilicate glass capillary electrode with internal solution connected to a Multi-Clamp Amplifier (Molecular Devices, San Jose, CA, USA). Recording pipettes were filled with intracellular solution (in mM): $120 \mathrm{~K}-\mathrm{MeSO}_{3}, 10$ Hepes, $0.25 \mathrm{EGTA}, 2 \mathrm{MgCl}_{2}$, $0.1 \mathrm{CaCl}_{2}, 10 \mathrm{Na}_{2}$-Phosphocreatine, $4 \mathrm{Mg}$-ATP, and 0.3 Na-GTP ( $\mathrm{pH}$ 7.4). Patch pipettes (3 5 M $\Omega$ ) were pulled on a Narishige electrode puller PC-10 (Narishige, Tokyo, Japan) from Kimax borosilicate glass capillaries (TW150-4, World precision Instruments, Inc., Sarasota, FL, USA) with an inner diameter of $1.12 \mathrm{~mm}$ and an outer diameter of $1.5 \mathrm{~mm}$. The analog signal was digitized by an A/D converter (Digidata 1440A, Molecular Devices) and collected with pClamp10.7 software (Molecular Devices). Currents were Bessel-filtered at a cut-off frequency of $5 \mathrm{kHz}$ and digitally sampled at $10 \mathrm{kHz}$. Including measuring resting membrane potential, all recording was performed in $\mathrm{nACSF}$.

\section{Distinguishing interneurons from pyramidal neurons in mPFC, and statistical analysis}

The neurons in mPFC were divided into two types, pyramidal neuron and interneuron. Pyramidal neuron which has a triangular shape is relatively large in size $\left(\mathrm{C}_{\mathrm{m}}, 120 \sim 140 \mathrm{pF}\right)$, and regulated by interneuron, whereas interneuron which has a circular shape is relatively small in size $\left(\mathrm{C}_{\mathrm{m}}, 25 \sim 30 \mathrm{pF}\right)$, and has the ability to control pyramidal neuron [20]. To characterize pyramidal neurons and interneurons, we determined intrinsic properties of neuron, such as input resistance, membrane capacitance, membrane resistance of neuron, and resting membrane potential (RMP) values (Table 1). Data were presented as mean \pm standard error of the mean and analyzed using Prism 8 software (GraphPad Software Inc, USA). For multiple comparisons, one-way repeated measures analysis of variance (ANOVA) followed by post hoc Tukey's multiple com-

Table 1. Electrophysiological properties of pyramidal and interneurons in single-, pair-exposed rats and naïve rats in mPFC

\begin{tabular}{|c|c|c|c|c|c|c|}
\hline & \multicolumn{3}{|c|}{ Pyramidal } & \multicolumn{3}{|c|}{ Interneuron } \\
\hline & Single & Pair & Naïve & Single & Pair & Naïve \\
\hline $\mathrm{C}_{\mathrm{m}}(\mathrm{pA})$ & $\begin{array}{c}58.92 \pm 4.17 \\
\quad(n=21)\end{array}$ & $\begin{array}{c}67.78 \pm 4.73 \\
(n=18)\end{array}$ & $\begin{array}{c}56.42 \pm 3.73 \\
(n=36)\end{array}$ & $\begin{array}{c}24.83 \pm 1.74 \\
(n=19)\end{array}$ & $\begin{array}{r}27.02 \pm 0.9 \\
(n=17)\end{array}$ & $\begin{array}{c}30.07 \pm 3.49 \\
(n=18)\end{array}$ \\
\hline $\mathrm{R}_{\mathrm{m}}(\mathrm{M} \Omega)$ & $\begin{array}{c}94.23 \pm 8.99^{\star *} \\
(n=21)\end{array}$ & $\begin{array}{c}103.25 \pm 16.9^{*} \\
(n=18)\end{array}$ & $\begin{array}{c}209.29 \pm 24.78 \\
(n=36)\end{array}$ & $\begin{array}{c}273.5 \pm 56.75 \\
(n=19)\end{array}$ & $\begin{array}{c}284.28 \pm 35.37 \\
(n=17)\end{array}$ & $\begin{array}{c}282.04 \pm 41.32 \\
(n=18)\end{array}$ \\
\hline $\operatorname{IR}(\mathrm{M} \Omega)$ & $\begin{array}{r}140 \pm 10 \\
(n=25)\end{array}$ & $\begin{array}{c}120 \pm 6^{*} \\
(n=20)\end{array}$ & $\begin{array}{c}180 \pm 8 \\
(n=38)\end{array}$ & $\begin{array}{c}190 \pm 10^{*} \\
(n=17)\end{array}$ & $\begin{array}{c}260 \pm 30^{\# \#} \\
(n=18)\end{array}$ & $\begin{array}{r}250 \pm 10 \\
(n=19)\end{array}$ \\
\hline $\mathrm{RMP}(\mathrm{mV})$ & $\begin{array}{r}-74.79 \pm 2.7 \\
(n=23)\end{array}$ & $\begin{array}{c}-70.58 \pm 1.54 \\
(n=17)\end{array}$ & $\begin{array}{c}-73 \pm 3.01 \\
(n=7)\end{array}$ & $\begin{array}{c}-65.63 \pm 2.82 \\
(n=12)\end{array}$ & $\begin{array}{c}-64.12 \pm 2.28 \\
(n=17)\end{array}$ & $\begin{array}{c}-66.43 \pm 3.24 \\
(n=7)\end{array}$ \\
\hline
\end{tabular}

mPFC, medial prefrontal cortex; IR, input resistance; $C_{m}$, membrane capacitance; $R_{m}$, membrane resistance; RMP, resting membrane potential. Two-way ANOVA, Bonferroni post-hoc test: ${ }^{*} \mathrm{p}<0.05,{ }^{* *} \mathrm{p}<0.01$, compared with Naïve; \#\# $\mathrm{p}<0.01$, compared with Single. 
parison test, and two-way repeated measures ANOVA followed by Bonferroni post-hoc tests were used. Asterisks indicate statistically significant differences among the groups.

\section{RESULTS}

Significant differences in freezing and passive avoidance behaviors between single-, pair-exposed rats and naïve rats during retention period

We compared the differences between the fear-related behaviors of single-, pair-exposed rats and naive rats using the passive avoidance test to determine the effect of pair-exposed social buffering condition on electric shock-induced fear response. The schematic timeline of the experimental procedures is presented in Fig. 1A.

In the retention session, the duration of freezing behavior (Fig. 1B; Single, 156.7 $\pm 33.95, n=9$; Pair, 29.9 $\pm 15.83, n=10$, Naïve, $21.86 \pm 11.43, n=7$; One-way ANOVA, Tukey's post-hoc test, Single vs. Pair, ${ }^{* *} \mathrm{p}=0.002$, Single vs. Naïve, $\left.{ }^{* *} \mathrm{p}=0.002\right)$ and step-through latency for entry into the black compartment (Single, 177.9 \pm 47.29 , $n=9$; Pair, 27.1 $\pm 16.46, n=10$, Naïve, $40.29 \pm 15.61, n=7$; One-way ANOVA, Tukey's post-hoc test, Single vs. Pair, ${ }^{* *} \mathrm{p}=0.005$, Single vs. Naïve, $\left.{ }^{*} \mathrm{p}=0.019\right)$ showed a greater decrease in pair-exposed rats and naive rats than that in single-exposed rats. Moreover, the black-compartment preference (Single, 20.78 $\pm 10.51, n=9$; Pair, $67.3 \pm 5.8, n=10$, Naïve, $61.57 \pm 8.14, n=7$; One-way ANOVA, Tukey's post-hoc test, Single vs. Pair, ${ }^{* *} \mathrm{p}=0.001$, Single vs. Naïve, ${ }^{* *} \mathrm{p}=0.008$ ) and number of entries into the black compartment (Single, $1.33 \pm 0.55, n=9$; Pair, $4.5 \pm 0.7, n=10$, Naïve, $4.5 \pm 1.21, n=7$; One-way ANOVA, Tukey's post-hoc test, Single vs. Pair, ${ }^{\star} \mathrm{p}=0.02$, Single vs. Naïve, ${ }^{*} \mathrm{p}=0.032$ ) showed a greater increase in pair-exposed rats and naïve rats than that in single-exposed rats. These results are consistent with those of previous studies [19], suggesting that pair exposure to conspecific organisms during fear conditioning aids in the fear-coping mechanism in the freezing response and fear memory behaviors to the naïve level.

\section{Intrinsic electrophysiological properties of neurons in the MPFC in single-, pair-exposed rats and naïve rats}

Studies have suggested that the $\mathrm{MPFC}$ is a critical area in the circuitry that controls social behavior [21], and the PL of the mPFC is known as a modulatory area for fear memory conditioning [22]. We assessed the effect of the pair-exposed circumstance on the electrophysiological properties of neurons in the PL of the mPFC to determine whether the pair-exposed social condition modulated mPFC activity.

We used current-clamp patch recording protocol to measure intrinsic electrophysiological properties and observe spikes in pyramidal neurons and fast-spiking (FS) interneurons. There was not significantly different resting membrane potential among three groups in pyramidal neurons and interneurons (Table 1). We estimated I V curve to compare electric properties and neuron types among assigned groups (Fig. 2A). We measured input resistance (IR), membrane capacitance $\left(\mathrm{C}_{\mathrm{m}}\right)$ and membrane resistance $\left(R_{m}\right)$ of pyramidal neurons and interneurons in single-, pair-exposed rats and naïve rats. Cell type had a significant effect $(\mathrm{F}(1,131)=57.18, \mathrm{p}<0.0001)$ and the effects of $\operatorname{IR}(\mathrm{F}(2,131)=6.24$, $\mathrm{p}<0.01)$ and cell type $\times$ IR interaction $(\mathrm{F}(2,131)=4.62, \mathrm{p}<0.05)$ also had a significant effect, as determined by the two-way ANOVA. The IR of pyramidal neurons significantly decreased in pairexposed rats compared to naïve rats, and the IR of interneuron significantly decreased in single-exposed rats compared to pairexposed and naïve rats (Table 1 ). Cell type had a significant effect $(\mathrm{F}(1,113)=90.53, \mathrm{p}<0.0001)$, but the effects of $\mathrm{C}_{\mathrm{m}}(\mathrm{F}(2,113)=0.85$, $\mathrm{p}>0.05)$ and cell type $\times \mathrm{C}_{\mathrm{m}}$ interaction $(\mathrm{F}(2,113)=1.68, \mathrm{p}>0.05)$ were not significant, as determined by the two-way ANOVA. The $\mathrm{C}_{\mathrm{m}}$ of interneurons significantly decreased compared to that of the pyramidal neurons, but there was no significant difference among assigned groups (Table 1$)$. The effect of cell type was significant ( $F$ $(1,113)=29.88 ; \mathrm{p}<0.0001)$, but the effects of $\mathrm{R}_{\mathrm{m}}(\mathrm{F}(2,113)=2.42$; $\mathrm{p}=0.09)$ and cell type $\times \mathrm{R}_{\mathrm{m}}$ interaction $(\mathrm{F}(2,113)=2.19 ; \mathrm{p}=0.116)$ were not significant, as determined by the two-way ANOVA. The $\mathrm{R}_{\mathrm{m}}$ of interneurons significantly increased compared to that of the pyramidal neurons, and the pyramidal neurons increased significantly in naïve rats compared to single- and pair-exposed rats (Table 1).

The number of action potential (AP) spikes in the pyramidal neurons and interneurons were investigated among single-, pairexposed rats and naïve rats. The number of AP spikes in pyramidal neurons revealed significant differences between in pair-exposed rats and naïve rats at 100 and $200 \mathrm{pA}$ current injection (Fig. 2B Left; Single: 50 pA, 3.57 $\pm 1.19, n=23,100$ pA, 8.52 $\pm 2.14, n=23$, 200 pA, 21.78 $\pm 2.5, n=23$; Pair: 50 pA, 0.59 $\pm 0.41, n=17,100$ pA, $11.58 \pm 1.9, n=17,200 \mathrm{pA}, 25.7 \pm 2.67, n=17$; Naïve: $50 \mathrm{pA}, 4.36 \pm 1.23$, $n=33,100$ pA, 11.58 $\pm 1.9, n=33,200$ pA, 25.7 $\pm 2.67, n=33$; Bonferroni post-hoc test, $100 \mathrm{pA}$ : Pair vs. Naïve, ${ }^{\star} \mathrm{p}=0.023,200 \mathrm{pA}$ : Pair vs. Naïve, $\left.{ }^{\star} \mathrm{p}=0.047\right)$. There was a considerably significant increase in the number of AP spikes in the interneurons in pair- and singleexposed rats compared to that in naïve rats especially at 200

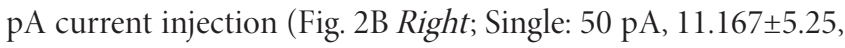
$n=12,100 \mathrm{pA}, 45.17 \pm 11.79, n=12,200 \mathrm{pA}, 117.42 \pm 17.17, n=12$; Pair: 50 pA, 6.41 $\pm 2.88, n=17,100$ pA, 49.12 $\pm 11.04, n=12,200$ pA, $101.82 \pm 13.41, n=12$; Naïve: $50 \mathrm{pA}, 12.94 \pm 3.47, n=18,100 \mathrm{pA}$, $24.11 \pm 6.12, n=18,200$ pA, 37.94 $\pm 10.16, n=18$; Bonferroni post-

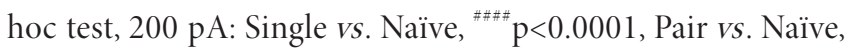


A

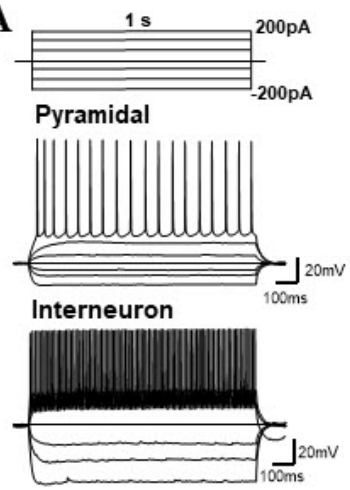

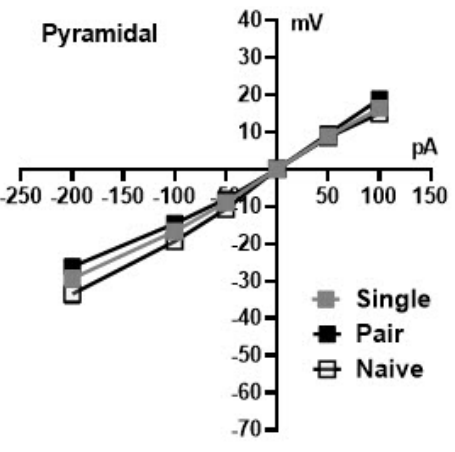

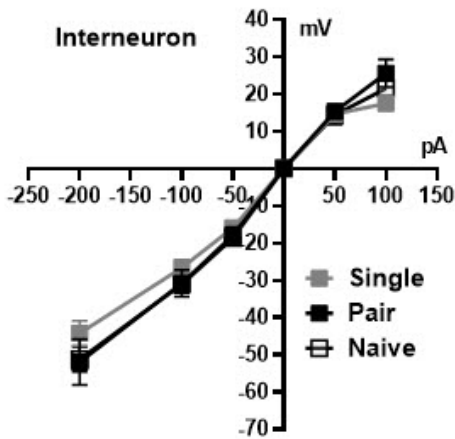

Fig. 2. I V curve and difference of number of spikes in single-, pair-exposed rats and naïve rats. (A) Left, Voltage responses to a depolarizing or hyperpolarizing pulse about 50, 100 and $200 \mathrm{pA}$ to estimate electrophysiological properties (Top) and the representative sample of pyramidal neuron and interneuron pattern (Bottom). Right, I V curve in pyramidal neuron and interneuron showed different slope. (B) There was a significant difference between the number of AP spikes in the pyramidal neurons of naive rats and pair-exposed rats at 100 and $200 \mathrm{pA}$ current injection (Pair vs. Naïve, Bonferroni post-hoc test, ${ }^{*} \mathrm{p}<0.05$ ), whereas the number of AP spikes in the interneurons was increased in single- and pair-exposed rats compared to naive rats at $200 \mathrm{pA}$ current injection (Pair vs. Naïve, ${ }^{* * * *} \mathrm{p}<0.0001$; Single vs. Naïve, ${ }^{\# \# \# \# ~} \mathrm{p}<0.0001$; Bonferroni post-hoc test).

$\left.{ }^{* * *} \mathrm{p}<0.0001\right)$. These data indicate that the number of AP spikes in the interneurons significantly increased in single- and pairexposed rats, but the number of AP spikes in pyramidal neurons significantly decreased in only pair-exposed rats compared with naïve rats.

\section{Reduction of AP spikes number in pyramidal neurons in both single-, pair-exposed rats and naïve rats by oxytocin}

To determine the alteration in the oxytocin-induced patterns in the pyramidal neurons, we compared the alteration in the number of AP spikes induced by oxytocin among single-, pair-exposed rats and naïve rats. Because when oxytocin treated, there showed both patterns of change in the number of spikes, increase and decrease pattern $[18,23,24]$, we differentiated and analyzed the pattern of oxytocin-induced spikes and checked the dominant pattern compared between single- and pair-exposed rats. Two patterns of oxytocin-induced changes were observed in pyramidal neurons in assigned rats: increase and decrease (Fig. 3 ).

In single-exposed rats, 10 of the 25 cells showed an increasing pattern (Control, 20.7 \pm 4.7 ; Oxytocin, 22.3 $\pm 5.19 ; n=10$; ${ }^{*} \mathrm{p}=0.037$, Paired $t$-test), and 15 showed a decreasing pattern (Control, $21.4 \pm 2.5$; Oxytocin, $16.8 \pm 2.7 ; n=15 ;{ }^{* *} \mathrm{p}=0.002$, Paired $t$-test; Fig. $3 \mathrm{~A})$. All spike pattern number in pyramidal neurons of single- exposed rats significantly decreased by the application of oxytocin (Control, 21.12 \pm 2.34 ; Oxytocin, $19 \pm 2.63 ; n=25 ;{ }^{*} \mathrm{p}=0.039$, Paired $t$-test; Fig. 3B). In pair-exposed rats, 4 the 19 cells showed an increasing pattern (Control, 15.25 \pm 1.8 ; Oxytocin, 16.75 $\pm 1.7 ; n=4$; ${ }^{\star} \mathrm{p}=0.014$, Paired $t$-test), and 15 showed a decreasing pattern (Control, 18.2 \pm 2.02 ; Oxytocin, $14.33 \pm 1.64 ; n=15 ;{ }^{* * *} \mathrm{p}<0.0001$, Paired $t$-test; Fig. 3C). Total spike pattern number in pyramidal neurons of pair-exposed rats significantly decreased by oxytocin (Control, 17.58 \pm 1.64 ; Oxytocin, $14.84 \pm 1.35 ; n=19 ;{ }^{* *} \mathrm{p}=0.001$, Paired $t$ test; Fig. 3D). These findings indicate that oxytocin-induced AP spikes in pyramidal neurons tended to decrease in both singleand pair-exposed rats, but no difference was observed between the oxytocin-induced alteration pattern in the number of AP spikes in the pyramidal neurons of single- and pair-exposed rats.

\section{Oxytocin-induced changes in the number of AP spikes in the interneurons in single-, pair-exposed rats and naïve rats}

The oxytocin-induced patterns in interneurons revealed patterns of increase and decrease in single- and pair-exposed rats (Fig. 4). In single-exposed rats, 4 of the 16 cells showed an increasing pattern (Control, 113.5 \pm 20.89 ; Oxytocin, $121 \pm 22.33 ; n=4 ;{ }^{*} \mathrm{p}=0.036$, Paired $t$-test), and 12 showed a decreasing pattern (Control, 125.8 \pm 15.45 ; 

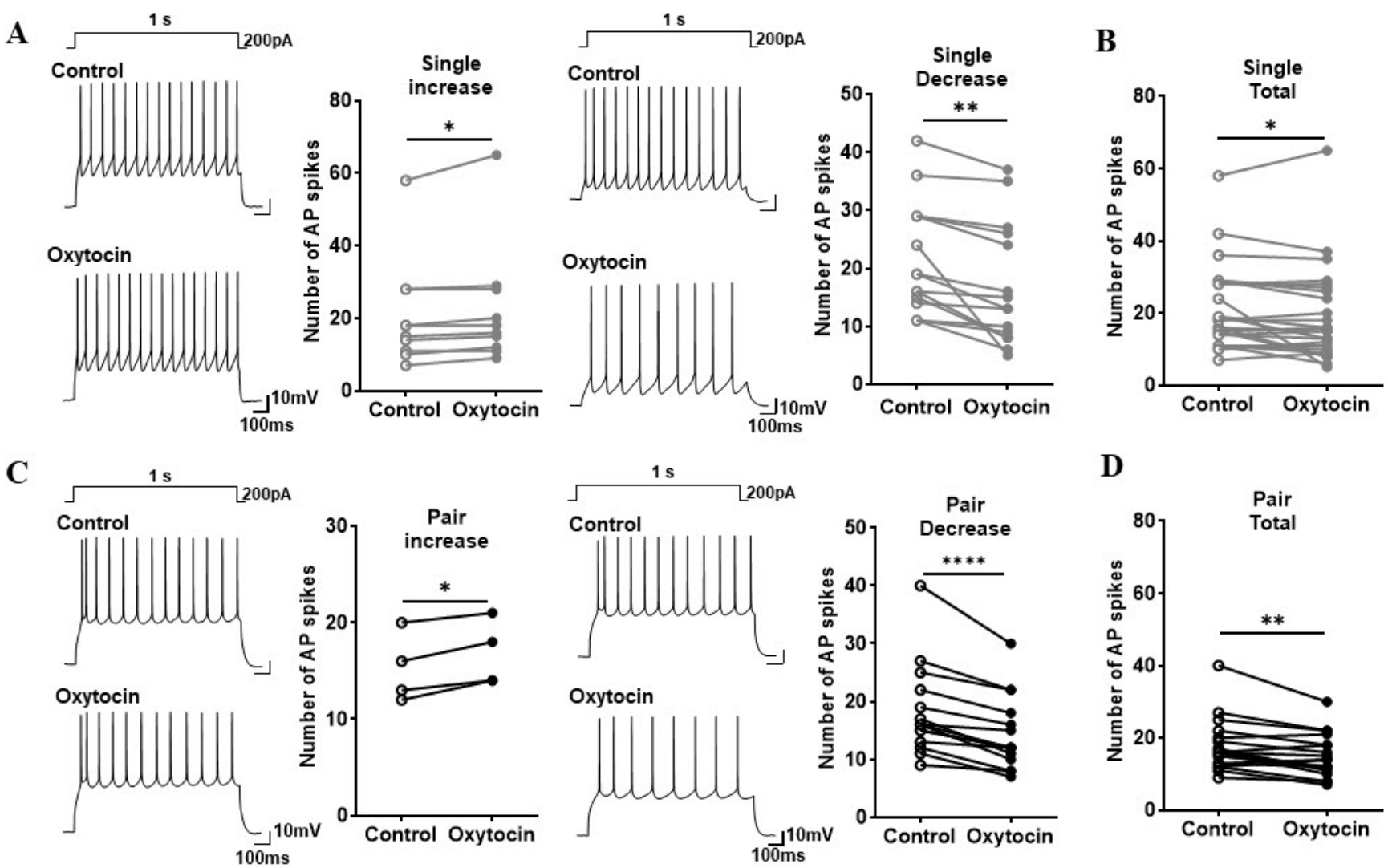

Fig. 3. Similar changes in the pattern of oxytocin-induced AP spike number in pyramidal neurons in single- and pair-exposed rats. (A, B) Singleexposed rats. (C, D) Pair-exposed rats. (A, C) Representative AP spike traces in pyramidal neuron to a depolarizing pulse (200 pA current injection for $1 \mathrm{~s}$ ) in the absence (Control) and the presence of oxytocin (Oxytocin), and a graph of the statistical values (Left, increase; Right, decrease) are shown (Paired $t$-test, ${ }^{*} \mathrm{p}<0.05,{ }^{* *} \mathrm{p}<0.01 ;{ }^{* * *} \mathrm{p}<0.0001$ ). AP, action potential. (B, D) Total number of AP spikes (Paired $t$-test, ${ }^{*} \mathrm{p}<0.05,{ }^{* *} \mathrm{p}<0.01$ ).

Oxytocin, 96.83 $\pm 17.59 ; n=12 ;{ }^{* *} \mathrm{p}=0.001$, Paired $t$-test; Fig. 4A). Total number of spikes in interneuron significantly decreased in single-exposed rats by oxytocin (Control, 122.8 \pm 12.45 ; Oxytocin, $102.9 \pm 14.23 ; n=16 ;{ }^{* *} \mathrm{p}=0.008$, Paired $t$-test; Fig. 4B). In pairexposed rats, 4 of the 17 cells showed an increasing pattern (Control, 72 \pm 24.26 ; Oxytocin, $109.8 \pm 15.74, n=4 ;{ }^{*} \mathrm{p}=0.03$, Paired $t$-test), and 13 cells showed a decreasing pattern (Control, 120.2 \pm 12.31 ; Oxytocin, $103.2 \pm 14.08 ; n=13 ;{ }^{* *} \mathrm{p}=0.001$, Paired $t$-test; Fig. $4 \mathrm{C}$ ). There was no significant difference in total number of spikes in interneuron of pair-exposed rats by oxytocin (Control, 108.8 \pm 11.79 ; Oxytocin, 104.7 $\pm 11.19 ; n=17$; $\mathrm{p}>0.05$, paired $t$-test; Fig. 4D).

These results show that the number of AP in the interneurons decreased in single-exposed rats by oxytocin, whereas this pattern by oxytocin was not corresponding in pair-exposed rats, suggesting that oxytocin is regulated in different ways in the interneurons of single- and pair-exposed rats.
Difference in the patterns of oxytocin-induced change in the number of AP spikes in interneurons between single-, pair-exposed rats and nä̈ve rats

The difference between the oxytocin-induced alteration in the number of AP spikes between single-, pair-exposed rats and naïve rats was compared to that of the controls to statistically clarify the change in AP spikes induced by oxytocin. Pyramidal neurons showed an oxytocin-induced reduction in the number of AP spikes in all assigned rats (Left, Pyramidal neuron: Single, $-2.12 \pm 0.97, n=25$; Pair, $-2.74 \pm 0.7, n=19$, Naïve, $-7.29 \pm 2.99, n=7$, Pyramidal: ${ }^{*} \mathrm{p}<0.05$; Right, Interneuron: Single, $-19.88 \pm 6.49, n=16$; Pair, $-4.12 \pm 6.74, n=17$, Naïve, $-18.57 \pm 13.12, n=7$; Tukey's multiple comparison test; Fig. 5). Interneurons showed a reduction in the number of AP spikes in single-exposed rats and naïve rats, but there was the lack of a significant difference in AP spikes in pairexposed rats by oxytocin. In summary, a decreased pattern of AP number by oxytocin in the pyramidal neurons was observed in naive rats than single-, pair-exposed rats, whereas in interneurons, there was a decreased pattern of AP number by oxytocin in single- 
A

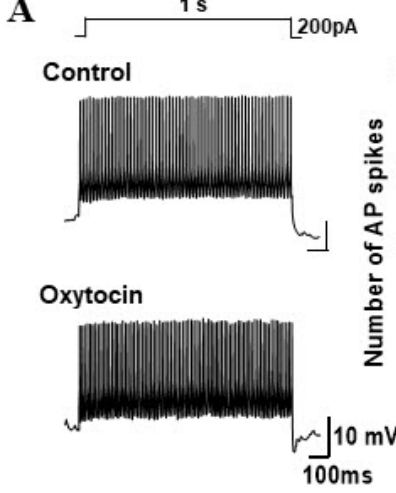

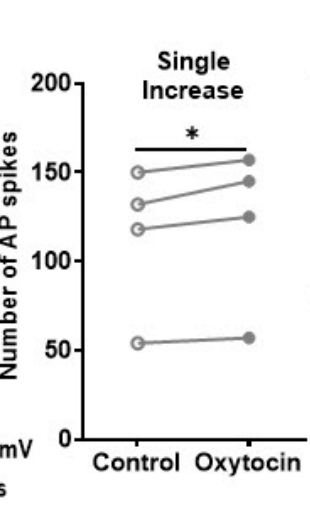

C

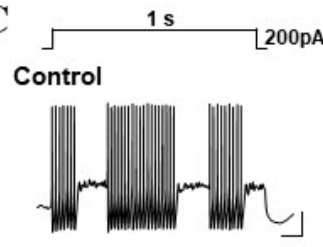

Oxytocin

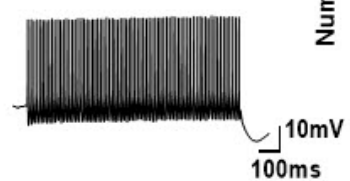

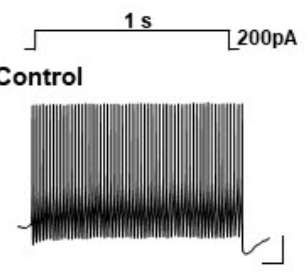

Oxytocin

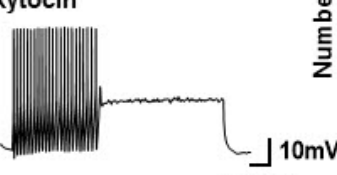

$100 \mathrm{~ms}$
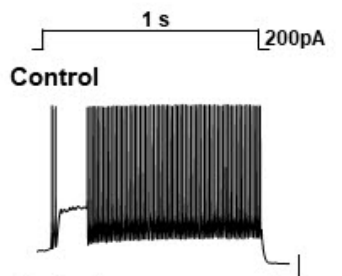

Oxytocin

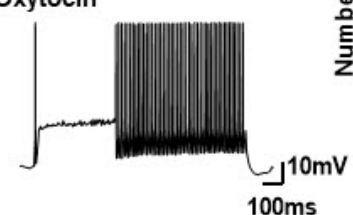

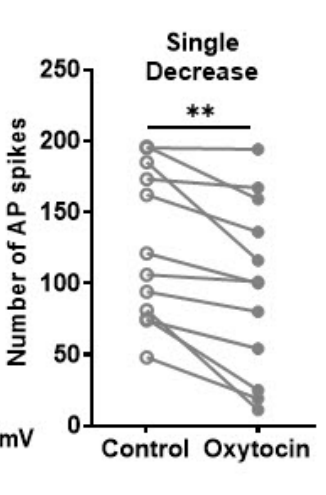

B
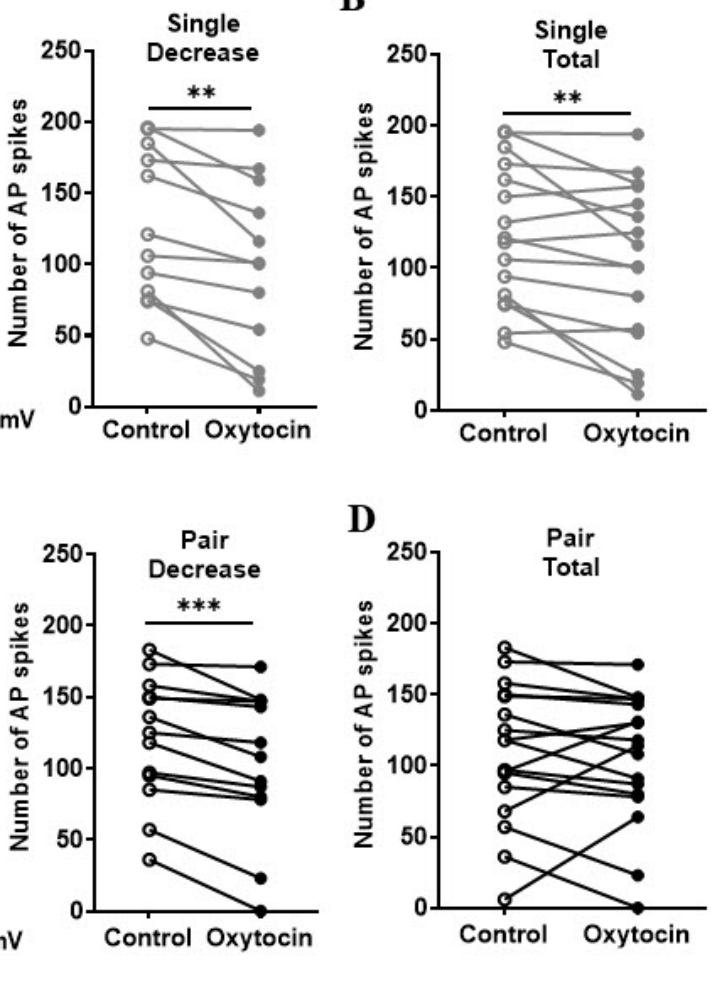

Fig. 4. Alteration in the number of oxytocin-induced AP spikes in interneurons in single- and pair-exposed rats. (A, B) Single-exposed rats. (C, D) Pairexposed rats. (A, C) Representative AP spike traces to a depolarizing pulse (200 pA current injection for 1s) in the absence (Control) and the presence of oxytocin (Oxytocin), and a graph of the statistical values (Left, increase; Right, decrease) are shown. (B, D) Total number of AP spikes (Paired $t$-test, $\left.{ }^{*} \mathrm{p}<0.05,{ }^{* *} \mathrm{p}<0.01,{ }^{* * *} \mathrm{p}<0.001\right)$. AP, action potential.
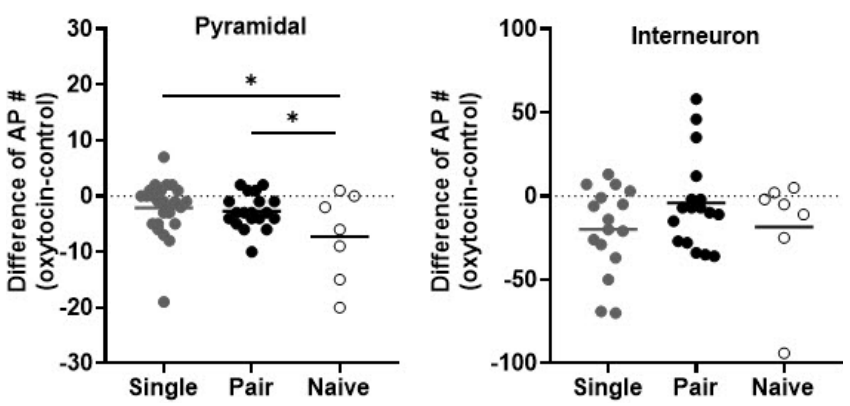

Fig. 5. Comparison of the oxytocin-induced changes in the number of AP spikes in single-, pair-exposed rats and naïve rats. Difference between the number of AP spikes in the oxytocin-treated and control conditions. In pyramidal neurons, there was a reduction in difference of AP \# in all assigned groups (One-way ANOVA, Tukey's multiple comparison test; ${ }^{*} \mathrm{p}<0.05 ;$ Left, Pyramidal neurons; Right, Interneurons). AP, action potential.

exposed rats and naïve rats, but no difference in pair-exposed rats.

In summary, pair-exposed rats exhibited a decrease in the number of AP spikes in the pyramidal neurons compared with singleexposed rats, suggesting that decreased neuronal activity elicited by social interaction induced a decreased fear response. Moreover, in interneurons of pair-exposed rats, the change of the number of AP spikes and an increase of input resistance also might possibly contribute to fear reduction. The different oxytocin effect of interneuron in pair-exposed rats compared with single-exposed rats and naive rats would offer the possibility that oxytocin plays a key role in social buffering reducing the fear response (Fig. 6).

\section{DISCUSSION}

This study verified the positive role of social buffering using the pair-exposed model, and determined its underlying mechanisms using the passive avoidance test and whole-cell patch currentclamp recording. A reduction in freezing behavior and increase in black-room preference was observed in the pair-exposed condition in the retention session of the behavioral test, suggesting that social interaction and social buffering (through pairing) induced a reduction in fear memory formation. The number of AP spikes in the interneurons in $\mathrm{mPFC}$ of single- and pair-exposed rats was not significantly different, but a significant decrease was observed in the number of AP spikes in the pyramidal neurons of pair-ex- 

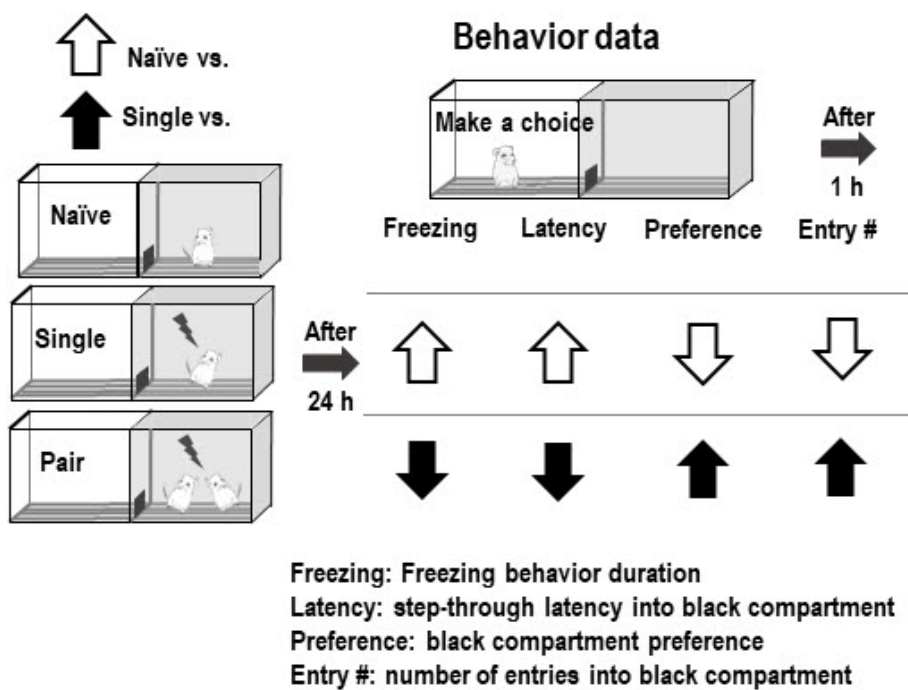

Recording data in PL mPFC

Entry \#: number of entries into black compartment

\section{PN: pyramidal neuron/ IN: interneuron \\ \# AP: number of action potential spike \\ OT: oxytocin}

IR: input resistance

Fig. 6. Summary to illustrate the role of neurons in the mPFC in social buffering and the mechanism in reducing the fear response. Decreased pyramidal neuronal activity in pair-exposed rats produces a decreased fear response. Differential oxytocin-mediated interneuronal activity would produce a social buffering action. Latency, step-through latency into black compartment; Preference, black compartment preference; Entry \#, number of entries into black compartment; IR, input resistance; PN, pyramidal neuron; IN, interneuron; \# AP, number of action potential spike; OT, oxytocin.

posed rats. A decrease in the number of AP spikes in the pyramidal neurons of pair-exposed rats is suggestive of a social interaction effect via pairing, which is consistent with previous research that reported that the excitation/inhibition balance maintained by the FS interneurons in the mPFC is essential for social interaction and sociability [25]. The decrease in the activity of the pyramidal neurons reduced the activity of BLA in the MPFC-BLA circuit, which may have resulted in a decrease in the fear response. Moreover, the oxytocin-induced AP modulation in interneurons of pair-exposed rats was different compared to that of single-exposed rats and naïve rat (Fig. 6). We opine that oxytocin plays a key role in social interaction, and predict the possibility that single-exposed rats would act similar to pair-exposed rats, i.e., exposure to oxytocin in the mPFC would reduce the fear response in single-exposed rats. Therefore, it is necessary to determine the role of oxytocin in single-exposed rats in future studies.

Social animal models can be divided into social buffering with positive effects and social contagion with negative effects [26]. Also, it can be affected their familiar or housing condition. In this study, the familiar pair-exposed condition was less likely to form the fear memory than the single-exposed condition after the application of electric shock. Therefore, the pair-exposed condition in this study provided more of a social buffering effect than a social contagion effect. Previous studies have also shown that the application of social buffering to the fear expression session or learning session reduces the animals freezing behavior compared to the isolated condition $[27,28]$. Therefore, we think that social buffering not only reduces the formation of fear memory but can also affect the increase in fear extinction.

Oxytocin, which is a social hormone, is one of the social buffering factors that mitigate stress [3]. In human studies, the provision of social support and oxytocin exposure resulted in higher levels of calmness and decreased anxiety [29]. Moreover, it is thought that oxytocin action, via the mPFC, suppresses neuronal activity related to fear memory and activates neuronal activity related to fear extinction [30]. Hence, oxytocin plays an important role in fear memory in the mPFC and is, thus, vital to the study of the mechanism of action of oxytocin in the mPFC.

The E/I balance in the mPFC is thought to be a crucial mechanism for the functioning of the mPFC. E/I imbalance can inhibit the connection between the mediodorsal thalamus and mPFC, thereby inducing abnormalities in sociability [21]. Another study suggested that social behavior deficits improved with an increase in the activity of FS interneurons and a decrease in the activity of pyramidal neurons, which achieved the E/I balance [31]. E/I imbalance can result in diseases such as autism and schizophrenia and is thought to play a role in memory formation or in the persistence of the disturbance mechanism. This study suggests another mechanism that can interfere with memory formation against new negative stimuli.

The mPFC consists of two types of neurons: pyramidal neurons and interneurons. Generally, GABAergic interneurons that regulate pyramidal neurons are classified into regular spike nonpyramidal, FS interneurons, and low-threshold spiking (LTS) interneu- 
rons [32, 33]. FS interneurons (former name: PV interneuron) and LTS interneurons (former name: somatostatin interneurons) can be distinguished by the shape of AP spike [34]. FS interneurons are thought to play an important role in social interaction; hence, they are strongly expected to contribute to the effects of social buffering [25]. FS interneurons were mainly targeted in this study; our results suggest that the pattern difference in interneurons represents the difference in the functionality of the $\mathrm{mPFC}$ itself, resulting in a change in the fear behavior. However, it is necessary to differentiate between the different types of interneurons and determine their mechanisms in detail in future studies.

Several factors can indicate a change in the number of AP spikes. The first is the change in the resting membrane potential (RMP). A change in the number of AP spikes due to changes in the RMP caused by oxytocin would be expected; however, significant differences were not observed in the RMP of the assigned rats in this study. Other studies reported that the number of AP spikes increased after oxytocin exposure, while no change was observed in the RMP [24]. Second, oxytocin may have changed the threshold of the AP, which may have indicated a change in the number of spikes. Other studies reported that injection of the oxytocin agonist TGOT into the anterior olfactory nucleus neurons resulted in a reduced threshold for the increase in the spike rate [35]. Finally, oxytocin can induce the influx of calcium through various channels, which can result in a change in the AP, if calcium is introduced through channels, such as N-type voltage-gated calcium channels or transient receptor potential vanilloid (TRPV) 2 and TRPV4, among others $[36,37]$. Such oxytocin-induced changes in the AP spike have a variety of causes, and future verification of this aspect will determine the mechanism by which oxytocin may have affected the AP spike.

In summary, this study confirmed that the formation of the fear response and fear memory was reduced under the pair-exposed condition, i.e., social buffering, while the number of AP spikes in pair-exposed rats decreased in the PL of the mPFC compared to that in single-exposed rats. Future studies are needed to determine how the coordination between the MPFC-BLA circuit connections affects social buffering in the fear condition, thereby identifying social buffering mechanisms at the neural network level. The synaptic level of E/I balance must be demonstrated to clarify the role of interneurons in social buffering in detail. We also think that the direct association between oxytocin and social buffering presented in this study can be clearly determined if the modification of behavioral patterns by social buffering via treatment with oxytocin agonists and antagonists is identified in vivo.

\section{ACKNOWLEDGEMENTS}

The present research was conducted by the research fund of Dankook University in 2018.

\section{REFERENCES}

1. Hennessy MB, Kaiser S, Sachser N (2009) Social buffering of the stress response: diversity, mechanisms, and functions. Front Neuroendocrinol 30:470-482.

2. Cohen S (2004) Social relationships and health. Am Psychol 59:676-684.

3. Smith AS, Wang Z (2014) Hypothalamic oxytocin mediates social buffering of the stress response. Biol Psychiatry 76:281288.

4. Ishii A, Kiyokawa Y, Takeuchi Y, Mori Y (2016) Social buffering ameliorates conditioned fear responses in female rats. Horm Behav 81:53-58.

5. Mikami K, Kiyokawa Y, Takeuchi Y, Mori Y (2016) Social buffering enhances extinction of conditioned fear responses in male rats. Physiol Behav 163:123-128.

6. Fuzzo F, Matsumoto J, Kiyokawa Y, Takeuchi Y, Ono T, Nishijo H (2015) Social buffering suppresses fear-associated activation of the lateral amygdala in male rats: behavioral and neurophysiological evidence. Front Neurosci 9:99.

7. López-Gutiérrez MF, Ortiz JJ, Camacho FJ, Young LJ, Paredes RG, Diaz NF, Portillo W, Alcauter S. Social bonding induces changes in brain functional connectivity in male and female monogamous voles: a longitudinal fMRI study. BioRxiv. 752345 [Preprint]. 2019 [cited 2019 Sep 5]. Available from: https://doi.org/10.1101/752345.

8. Minami C, Shimizu T, Mitani A (2017) Neural activity in the prelimbic and infralimbic cortices of freely moving rats during social interaction: effect of isolation rearing. PLoS One 12: e0176740.

9. Marcondes LA, Nachtigall EG, Zanluchi A, de Carvalho Myskiw J, Izquierdo I, Furini CRG (2020) Involvement of medial prefrontal cortex NMDA and AMPA/kainate glutamate receptors in social recognition memory consolidation. Neurobiol Learn Mem 168:107153.

10. Onoda K, Okamoto Y, Nakashima K, Nittono H, Ura M, Yamawaki S (2009) Decreased ventral anterior cingulate cortex activity is associated with reduced social pain during emotional support. Soc Neurosci 4:443-454.

11. Shapiro LE, Insel TR (1992) Oxytocin receptor distribution reflects social organization in monogamous and polygamous voles. Ann N Y Acad Sci 652:448-451. 
12. Donovan M, Liu Y, Wang Z (2018) Anxiety-like behavior and neuropeptide receptor expression in male and female prairie voles: the effects of stress and social buffering. Behav Brain Res 342:70-78.

13. Branchi I, Curley JP, D’Andrea I, Cirulli F, Champagne FA, Alleva E (2013) Early interactions with mother and peers independently build adult social skills and shape BDNF and oxytocin receptor brain levels. Psychoneuroendocrinology 38:522-532.

14. Smeltzer MD, Curtis JT, Aragona BJ, Wang Z (2006) Dopamine, oxytocin, and vasopressin receptor binding in the medial prefrontal cortex of monogamous and promiscuous voles. Neurosci Lett 394:146-151.

15. Li Q, Zhang B, Cao H, Liu W, Guo F, Shen F, Ye B, Liu H, Li Y, Liu Z (2020) Oxytocin Exerts Antidepressant-like effect by potentiating dopaminergic synaptic transmission in the mPFC. Neuropharmacology 162:107836.

16. Brill-Maoz N, Maroun M (2016) Extinction of fear is facilitated by social presence: synergism with prefrontal oxytocin. Psychoneuroendocrinology 66:75-81.

17. Macbeth AH, Lee HJ, Edds J, Young WS 3rd (2009) Oxytocin and the oxytocin receptor underlie intrastrain, but not interstrain, social recognition. Genes Brain Behav 8:558-567.

18. Tan Y, Singhal SM, Harden SW, Cahill KM, Nguyen DM, Colon-Perez LM, Sahagian TJ, Thinschmidt JS, de Kloet AD, Febo M, Frazier CJ, Krause EG (2019) Oxytocin receptors are expressed by glutamatergic prefrontal cortical neurons that selectively modulate social recognition. J Neurosci 39:32493263.

19. Lee H, Noh J (2016) Pair exposure with conspecific during fear conditioning induces the link between freezing and passive avoidance behaviors in rats. Neurosci Res 108:40-45.

20. Rotaru DC, van Woerden GM, Wallaard I, Elgersma Y (2018) Adult Ube3a gene reinstatement restores the electrophysiological deficits of prefrontal cortex layer 5 neurons in a mouse model of Angelman syndrome. J Neurosci 38:8011-8030.

21. Ferguson BR, Gao WJ (2018) Thalamic control of cognition and social behavior via regulation of gamma-aminobutyric acidergic signaling and excitation/inhibition balance in the medial prefrontal cortex. Biol Psychiatry 83:657-669.

22. Heroux NA, Robinson-Drummer PA, Sanders HR, Rosen JB, Stanton ME (2017) Differential involvement of the medial prefrontal cortex across variants of contextual fear conditioning. Learn Mem 24:322-330.

23. Marlin BJ, Mitre M, D'amour JA, Chao MV, Froemke RC (2015) Oxytocin enables maternal behaviour by balancing cortical inhibition. Nature 520:499-504.
24. Nakajima M, Görlich A, Heintz N (2014) Oxytocin modulates female sociosexual behavior through a specific class of prefrontal cortical interneurons. Cell 159:295-305.

25. Liu L, Xu H, Wang J, Li J, Tian Y, Zheng J, He M, Xu TL, Wu ZY, Li XM, Duan SM, Xu H (2020) Cell type-differential modulation of prefrontal cortical GABAergic interneurons on low gamma rhythm and social interaction. Sci Adv 6:eaay4073.

26. Panksepp J, Panksepp JB (2013) Toward a cross-species understanding of empathy. Trends Neurosci 36:489-496.

27. Kiyokawa Y, Kawai K, Takeuchi Y (2018) The benefits of social buffering are maintained regardless of the stress level of the subject rat and enhanced by more conspecifics. Physiol Behav 194:177-183.

28. Gutzeit VA, Ahuna K, Santos TL, Cunningham AM, Sadsad Rooney M, Muñoz Zamora A, Denny CA, Donaldson ZR (2020) Optogenetic reactivation of prefrontal social neural ensembles mimics social buffering of fear. Neuropsychopharmacology 45:1068-1077.

29. Heinrichs M, Baumgartner T, Kirschbaum C, Ehlert U (2003) Social support and oxytocin interact to suppress cortisol and subjective responses to psychosocial stress. Biol Psychiatry 54: 1389-1398.

30. Triana-Del Río R, van den Burg E, Stoop R, Hegoburu C (2019) Acute and long-lasting effects of oxytocin in corticolimbic circuits: consequences for fear recall and extinction. Psychopharmacology (Berl) 236:339-354.

31. Selimbeyoglu A, Kim CK, Inoue M, Lee SY, Hong ASO, Kauvar I, Ramakrishnan C, Fenno LE, Davidson TJ, Wright M, Deisseroth K (2017) Modulation of prefrontal cortex excitation/inhibition balance rescues social behavior in CNTNAP2-deficient mice. Sci Transl Med 9:eaah6733.

32. Gibson JR, Beierlein M, Connors BW (1999) Two networks of electrically coupled inhibitory neurons in neocortex. Nature 402:75-79.

33. Rudy B, Fishell G, Lee S, Hjerling-Leffler J (2011) Three groups of interneurons account for nearly $100 \%$ of neocortical GABAergic neurons. Dev Neurobiol 71:45-61.

34. Lee S, Hjerling-Leffler J, Zagha E, Fishell G, Rudy B (2010) The largest group of superficial neocortical GABAergic interneurons expresses ionotropic serotonin receptors. J Neurosci 30:16796-16808.

35. Oettl LL, Ravi N, Schneider M, Scheller MF, Schneider P, Mitre M, da Silva Gouveia M, Froemke RC, Chao MV, Young WS, Meyer-Lindenberg A, Grinevich V, Shusterman R, Kelsch W (2016) Oxytocin enhances social recognition by modulating cortical control of early olfactory processing. Neuron 90 : 609-621. 
36. Jurek B, Neumann ID (2018) The oxytocin receptor: from intracellular signaling to behavior. Physiol Rev 98:1805-1908.

37. Bakos J, Srancikova A, Havranek T, Bacova Z (2018) Molecu- lar mechanisms of oxytocin signaling at the synaptic connection. Neural Plast 2018:4864107. 